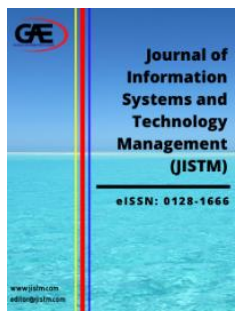

\author{
JOURNAL OF INFORMATION \\ SYSTEM AND TECHNOLOGY \\ MANAGEMENT (JISTM) \\ WWW.jistm.com
}

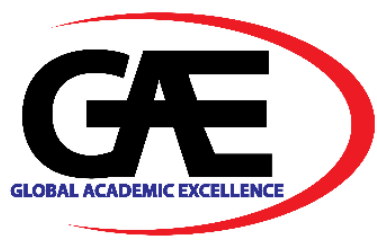

\title{
UNDERSTANDING USERS' SWITCHING INTENTION ON MOBILE WALLET
}

\author{
Lim Kah Boon ${ }^{1 *}$, Yeo Sook Fern ${ }^{2}$, Tan Choon Ching ${ }^{3}$
}

1 Faculty of Business, Multimedia University, Melaka, Malaysia

Email: kblim@mmu.edu.my

2 Faculty of Business, Multimedia University, Melaka, Malaysia

3 Faculty of Business, Multimedia University, Melaka, Malaysia

Corresponding Author

\section{Article Info:}

Article history:

Received date: 13.07 .2020

Revised date: 10.08 .2020

Accepted date: 30.09 .2020

Published date: 01.12.2020

\section{To cite this document:}

Lim, K. B., Yeo, S. F., \& Tan, C. C. (2020). Understanding User' Switching Intention on Mobile Wallet. Journal of Information System and Technology Management, 5 (19), 1424.

DOI: $10.35631 /$ JISTM.519002.

This work is licensed under $\underline{\mathrm{CC} B Y}$ 4.0 (ㅇ)(1)

\begin{abstract}
:
In the current era, mobile devices playing an important role in our part of daily life. With today's technology, users of mobile devices can now use their mobile device to make a payment or transaction instead of using a physical card. A mobile wallet is a way to display your card information in a digital format on your mobile device. As a result, mobile wallets are now growing rapidly in Malaysia and many mobile wallet service providers are available on the current market. For this reason, several issues have been raised in this research in order to study the factors that affect users ' intention to switch to mobile wallets. The main objective of this research is to examine the factors which affect users' switching intention on the mobile wallet. A set of self-administered questionnaires has been randomly distributed to 220 respondents for the purpose of data collection. After we had collected all the data from the respondents, data were keyed into Statistical Package for the Social Sciences (SPSS) Version 26 and Smart PLS is used to assess the measurement model and the structural equation model. The data analysis result showed that dissatisfaction, alternative attractiveness, and the subjective norm has a significant relationship towards users' switching intention on the mobile wallet. Moreover, the service provider should keep improving their service quality to avoid users switching to another one. Lastly, the service provider must keep updating their features or attractiveness, so the users won't be so easy to switch to another one and influence by other people.
\end{abstract}

Keywords:

Alternative Attractiveness, Dissatisfaction, Mobile Wallet, Subjective Norm, Switching Intention 


\section{Introduction}

In the present age, mobile device playing an important role in our part of life. Because of the technology nowadays, mobile device users now can use their mobile device to make a payment or transaction instead of using physical card. A mobile wallet is a way to carry your cards information in a digital form on your mobile device. Mobile wallet is a virtual wallet provided by some service providers, where people can reload a certain amount of money. The digital payment method functions as a cashless payment service, where consumer no need to pay with cash or even swipe their credit card or debit card from offline merchants (Ahuja \& Joshi, 2018). A mobile wallet protects your cash in a completely safe manner. It stores your payment information, for example, credit or debit cards, and cash balances that can be used to make payments. In order to combating theft, mobile wallets are based on encrypted software that works through mobile apps. They will discard your bank account by keeping an accurate check on your money. Similar to your traditional wallet, your mobile wallet can also store money for you to make payments and purchases. The only difference between these two is the form of money. Most importantly, those who are interested in using a mobile wallet for remittances can receive money from others. There are several advantages of sending money through a mobile money wallet. Firstly, its quick accessibility makes life much easier for the receiver. Once the money is received by the receiver, they can use it to pay bills or make purchases immediately. Second, there's no theft issue because the mobile wallet will be password protected. Another important point is that mobile wallets are incredibly user-friendly. Mobile wallet users can make transactions with just a click of a button while on the go. Finally, since these wallets are encrypted with a security layer, no sensitive data such as your bank details can be hacked, unlike direct credit or debit card payment.

Steinbach (2016) forecasted that the mobile wallet will change the consumer culture. In the digital revolution, it is a drastic event towards throwing out ancient, ratty wallet, cutting down those credit cards. The convergence of the growth of wireless telecommunications, multifunctional mobile devices and the growth of payment systems has developed the greatest chance of transacting in the true global in methods other than cash or card. Google captures this essence in its Google Wallet Vision Statement "In the past few thousand years, the way we pay has changed just three times - from coins, to paper money, to plastic cards. Now we're on the brink of the next big shift". Mobile wallet is the next big change. Mobile commerce began immediately when the mobile technology evolved into the capacities of short messaging services (SMS) (Carr, 2007). The thriving of mobile wallet is increasing the intensive competition between various mobile wallet platforms. Although there is a general upward trend in the mobile wallet industry, the success of the mobile wallet platform relies mainly on the original acceptance by the user and the intention of ongoing use. Because of the low switch cost and abundant choices, users can easily change from their current mobile wallet to another one, they can even have more than one mobile wallet simultaneously. Therefore, the service providers have to know what variables can cause the desire of the user to switch between different platforms (Song, Zhao, \& Sun, 2017).

Mobile wallet industry had been rapidly growing in Malaysia in these few years and it had influencing the Malaysia's economic growth. It has push towards Malaysia to a cashless society. According to PwC Malaysia's estimates, the mobile-wallet market is projected to grow to USD20 billion by 2024, underpinned by favourable industry growth dynamics and market potential (Tan, 2018). The mobile wallet industry can continually to provide more benefits to the users in order to attract more people to use mobile wallet. The industry must study all the 


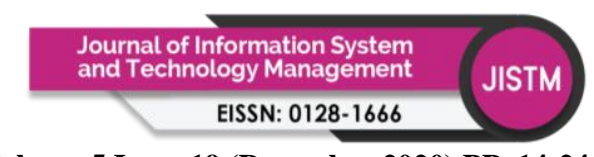

Volume 5 Issue 19 (December 2020) PP. 14-24 DOI: 10.35631/JISTM.519002

factors in order to understand users' switching intention on mobile wallet. Therefore, it will help the industry to growth and push towards Malaysia to a cashless society.

Hence, the main objective of this study is to investigate the factors that affecting users' switching intention on mobile wallet. The four main independent variables which involve in this study are dissatisfaction, trust, alternative attractiveness and subjective norm.

\section{Literature Review}

The dependent variable of this study is switching intention. Switching is one of the unfavourable behaviours that attracts a lot of attention in studies. It is referring to the user's migration from one service provider to another one (Ranganathan, Seo, \& Babad, 2006). The switching intention is not necessarily equal to user's abandonment of current service provider (Keaveney \& Parthasarathy, 2001). However, it might involve in a vibrant process that enables consumers to reduce the use of current service providers by enhancing the use of alternative service providers (Bhattacherjee, Limayem, \& Cheung, 2012). Based on the research from Wu et. al (2017), they had been examined the users switching intention on personal cloud storage service while Sun et al (2017) had explore the main factors of user's switching intention on mobile instant massage application. Chang et. al (2017) measured the intention of the consumers' channel to switch from physical to mobile shops. Switching behaviour is usually described as an intervention that the customer selects as an alternative to replacing the previous former service providers (Bansal, Taylor, \& James, 2005). Peng et al., (2014) and Peng et .al (2016) had researched mainly on the network roles, relative deprivation and trust on the intention of changing mobile wallet users by showing the theory of migration from the perspective of social networks.

Next, the discussion is focused on the independent variables of this study. First, satisfaction can be described as "the summary psychological state that result when the emotion surrounding disconfirmed expectations is combine with the consumer's previous feelings about the consumption experience" (Oliver, 1981). Therefore, service quality is also one of the most critical variables that directly affects the satisfaction of customers and indirectly affects the intention of use (Lien, Cao, \& Zhou, 2017; Kasiri et al., 2017). From the point of view of the product, usability emphasised the ease of using certain artefacts of technology to achieve the goals. Many studies have validated the positive correlation between usability and end-user satisfaction (Lee et al., 2015; Flavián, Guinalíu, \& Gurrea, 2006; Casaló, Flavián, \& Guinalíu, 2008). Human migration research has taken satisfaction and dissatisfaction as the main factor that driving people away from the initial location (Bansal, Taylor, \& James, 2005). The previous research studies have demonstrated the adverse effect of satisfaction on the intention of customers to change service providers such as email services (Kim \& Malhotra, 2005), blog services (Zhang, 2008) and web browser service (Ye, Potter, \& Potter, 2011). The majority of the users' switching intentions obtained from their dissatisfaction with the current service so as the opposite of satisfaction, dissatisfaction is expected to be more direct capture the users' psychological states to switch (Cheng, Yang, \& Lim, 2009).

\section{H1: There is a significant relationship between dissatisfaction and user's switching intention on mobile wallet.}

On the other hand, the notion of trust had been found out in multiple of fields such as marketing, e-commerce, business and etc. Nicolaou and McKnight (2006) considered trust as a system for 


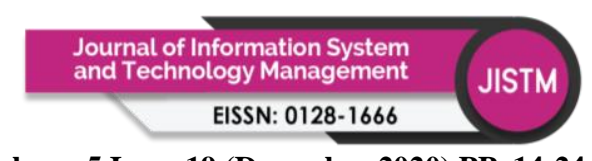

Volume 5 Issue 19 (December 2020) PP. 14-24 DOI: 10.35631/JISTM.519002

evaluating the magnitude of the beneficial results that consumers expect. Yoon (2002) had studied the connection between trust and users' switching intention and discovered that trust would influence the desire to switch. Bansal, Taylor and James (2005) showed that the intention to switch could be affected by certain factors, including trust. Khan et al. (2014) observed that a rise in value, business name, trust and word of mouth could lead to a shift of intent.

\section{H2: There is a significant relationship between trust and user's switching intention on mobile wallet.}

The third independent variable which is the alternative attractiveness can be related to the attitude of the user about the market accessibility of alternative decisions. It is regarded a significant switch behaviour predictor (Liu et al., 2016). There are numerous options for the users in the competitive mobile wallet sector. Users are more likely to move to the alternative when they perceive the main characteristics of an alternative mobile wallet service provider is better than the initial one (Cheng, Yang, \& Lim, 2009). The existing literatures showed that alternative attractiveness had a positive effect on user switching intention (Kim, Shin, \& Lee, 2006).

\section{H3: There is a significant relationship between alternative attractiveness and user's switching intention on mobile wallet.}

Lastly, subjective norm relates to the perception of an individual that important others believe that he or she should participate in a specific behaviour (Ajzen, 1991). The adoption and use decision of users could be significantly influenced by social variables such as the choice of significant, since their family, relatives and friends may be using a different type mobile wallet (Zhou \& Lu, 2011). It was discovered that subjective norm as a major social variable affects the readiness of users to turn to an option (Bansal, Taylor, \& James, 2005; Ye, Potter, \& Potter, 2011). Due to the suggestions from other people, user will have a greater switching intention and consider an alternative mobile wallet which is more attractive (Hou, 2015).

\section{H4: There is a significant relationship between subjective norm and user's switching intention on mobile wallet.}

\section{Methodology}

For the data collection purposes, we have randomly distributed 220 sets of self-administered questionnaires to those targeted respondents. The minimum required sample size based on the $\mathrm{G}^{*}$ power calculation is 138 respondents. A total of 200 sets of completed questionnaires are used for analysis purposes in this study. The successful response rate is $90.91 \%$. Data were collected through a convenience sampling method in this study. The set of questionnaires is distributed in three states of Malaysia which are Johor, Melaka and Selangor. There are three main sections in the set of questionnaires include demographic variables, the measurement items for independent and dependent variables. The four independent variables which studies in this study are dissatisfaction, trust, alternative attractiveness and subjective norm. All of the measurement items are measured based on the five-point Likert scale $(1=$ strongly disagree to $5=$ strongly agree). All of the measurement items for independent and dependent variables are adopted from Sun et al. (2017) to ensure content validity. After the data collection process, 


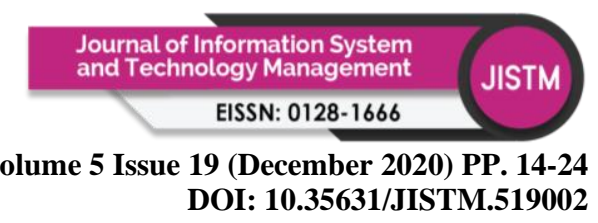

data were keyed into SPSS version 25 and followed by using Partial Least Square Structural Equation Modelling (PLS-SEM 3.2.7) to assess the hypothesis.

\section{Findings and Discussion}

The discussion of findings is first focused on the demographic profile of the respondents in this study. Table 1 summarise the demographic profile of the 200 respondents which have participated in this research. The male respondents are more than the female respondents which is $57.5 \%$ of the respondents were male while the remaining of $42.5 \%$ were female. This means that there is a total of 115 male respondents and 85 female respondents were participated in this research. The highest respondents of age group who had participated in this research is age between 18-24 years old which have 91 respondents (45.5\%) out of 200 respondents. Next, the age group of 25-31 years old have 59 respondents $(29.5 \%)$ out of 200 respondents. Moreover, the age group of 32-38 years old have 28 respondents (14\%) out of 200 respondents, follow by the age group of 39-45 years old have 14 respondents (7\%) out of 200 respondents. Lastly, the age group of above 45 years old is the lowest which is only have 8 respondents (4\%) out of 200 respondents. The highest respondents of monthly income are group of below RM1,000 which is 68 respondents (34\%) out of 200 respondents. Next, the monthly income group of RM2,000-RM2,999 consist of 52 respondents (26\%) out of 200 respondents. Then followed by monthly income group of RM1,000-RM1,999 which is 34 respondents (17\%) out of 200 respondents and monthly income group of RM3,000-RM3,999 which is 24 respondents (12\%) out of 200 respondents. Lastly, the lowest respondents of monthly income are group of RM4,000 and above which only consist of 22 respondents (11\%) out of 200 respondents. The highest proportion is Student which is 81 respondents (40.5\%) out of 200 respondents. Next, private sector contributed of 48 respondents (24\%) out of 200 respondents. Self-employed contributed of 33 respondents $(16.5 \%)$ out of 200 respondents. Furthermore, government servant also contributed 29 respondents $(14.5 \%)$ out of 200 respondents and 7 respondents (3.5\%) are categorise in the other category of occupation. Lastly, category of retired is the lowest proportion which is only 2 respondents $(1 \%)$ out of 200 respondents.

Table 1: Summary of Respondents' Profile

\begin{tabular}{|c|c|c|}
\hline Demographic profile & Frequency & Percentage (\%) \\
\hline \multicolumn{3}{|l|}{ Gender } \\
\hline Female & 85 & 42.5 \\
\hline Male & 115 & 57.5 \\
\hline \multicolumn{3}{|l|}{ Age } \\
\hline $18-24$ years old & 91 & 45.5 \\
\hline $25-31$ years old & 59 & 29.5 \\
\hline $32-38$ years old & 28 & 14 \\
\hline $39-45$ years old & 14 & 7 \\
\hline Above 45 years old & 8 & 4 \\
\hline \multicolumn{3}{|l|}{ Monthly Income } \\
\hline Less than RM2000 & 102 & 51 \\
\hline RM2000 - RM2999 & 52 & 26 \\
\hline RM3000 - RM3999 & 24 & 12 \\
\hline RM4000 and above & 22 & 11 \\
\hline \multicolumn{3}{|l|}{ Occupation } \\
\hline Government Servant & 29 & 14.5 \\
\hline Private sector & 48 & 24 \\
\hline
\end{tabular}


Volume 5 Issue 19 (December 2020) PP. 14-24 DOI: 10.35631/JISTM.519002

\begin{tabular}{ccc}
\hline Self-employed & 33 & 16.5 \\
Student & 81 & 40.5 \\
Retired & 2 & 1 \\
Others & 7 & 3.5 \\
\hline
\end{tabular}

Since PLS-SEM 3.2.7 software is used to analyse the data of this study, two models which are measurement model that relates indicator items to their relevant latent constructs and structural model which relates diverse latent constructs to each other are utilised in PLS analysis (Hair, Ringle \& Sarstedt, 2013). As suggested by Hair et al. (2013), a two-step analysis needs to be performed. In the first stage, the validity and reliability of the measurement model will be examined. Then, the analysis is followed with an examination of the structural model to study the research hypotheses. The summary findings of measurement model assessment against the criteria of internal consistency, indicator reliability and convergent validity with the values of outer loadings, AVE, composite reliability (CR), Cronbach alpha (CA) and Rho_A are illustrated in Table 2. Our result s show that all the item loadings are ranged from 0.891 to 0.957. According to Hair et al. (2014), the constructs' validity is convergent when the factor loading of the items is greater than 0.5 . This indicates that all the items loadings of this study are fulfilled the minimum requirement. The convergent validity of variables was examined by AVE, CR, CA and Rho_A. For this study, the value of CR, CA and Rho_A for all variables above 0.7 and AVE value are above 0.5 . This result indicates that the convergent validity of all variables has been established. On the other hand, Table 3 shows that all the values of Heterotrait-Monotrait (HTMT) criteria were lower than the required threshold value of HTMT 0.90 by Gold, Malhotra and Segars (2001).

Table 2: Convergent Validity Assessment

\begin{tabular}{|c|c|c|c|c|c|c|}
\hline $\begin{array}{l}\text { Model } \\
\text { construct }\end{array}$ & Items & Loadings & AVE & CR & CA & Rho_A \\
\hline \multirow{3}{*}{$\begin{array}{c}\text { Alternative } \\
\text { Attractiveness }\end{array}$} & AA1 & 0.901 & \multirow[t]{3}{*}{0.804} & \multirow[t]{3}{*}{0.925} & \multirow[t]{3}{*}{0.878} & \multirow[t]{3}{*}{0.879} \\
\hline & AA2 & 0.891 & & & & \\
\hline & AA3 & 0.899 & & & & \\
\hline \multirow{3}{*}{ Dissatisfaction } & D1 & 0.948 & \multirow[t]{3}{*}{0.895} & \multirow[t]{3}{*}{0.962} & \multirow[t]{3}{*}{0.941} & \multirow[t]{3}{*}{0.942} \\
\hline & D2 & 0.941 & & & & \\
\hline & D3 & 0.949 & & & & \\
\hline \multirow{2}{*}{$\begin{array}{l}\text { Subjective } \\
\text { Norm }\end{array}$} & SN2 & 0.935 & \multirow[t]{2}{*}{0.882} & \multirow[t]{2}{*}{0.938} & \multirow[t]{2}{*}{0.867} & \multirow[t]{2}{*}{0.869} \\
\hline & SN3 & 0.943 & & & & \\
\hline \multirow{3}{*}{$\begin{array}{l}\text { Switching } \\
\text { Intention }\end{array}$} & SI1 & 0.944 & \multirow[t]{3}{*}{0.891} & \multirow[t]{3}{*}{0.961} & \multirow[t]{3}{*}{0.939} & \multirow[t]{3}{*}{0.939} \\
\hline & SI2 & 0.930 & & & & \\
\hline & SI3 & 0.957 & & & & \\
\hline \multirow{3}{*}{ Trust } & $\mathrm{T} 1$ & 0.920 & \multirow[t]{3}{*}{0.855} & \multirow[t]{3}{*}{0.947} & \multirow[t]{3}{*}{0.915} & \multirow[t]{3}{*}{0.916} \\
\hline & $\mathrm{T} 2$ & 0.918 & & & & \\
\hline & T3 & 0.936 & & & & \\
\hline
\end{tabular}


Table 3: Heterotrait-Monotrait Ratio (HTMT) For Discriminant Validity

\begin{tabular}{cccccc}
\hline & $\begin{array}{c}\text { Alternative } \\
\text { Attractiveness }\end{array}$ & Dissatisfaction & $\begin{array}{c}\text { Subjective } \\
\text { Norm }\end{array}$ & $\begin{array}{c}\text { Switching } \\
\text { Intention }\end{array}$ & Trust \\
\hline $\begin{array}{c}\text { Alternative } \\
\text { Attractiveness }\end{array}$ & & & & & \\
\hline $\begin{array}{c}\text { Dissatisfaction } \\
\text { Subjective } \\
\text { Norm }\end{array}$ & 0.673 & 0.893 & 0.691 & & \\
\hline $\begin{array}{c}\text { Switching } \\
\text { Intention }\end{array}$ & 0.887 & 0.789 & 0.874 & & \\
\hline Trust & 0.784 & 0.623 & 0.767 & 0.744 & \\
\hline
\end{tabular}

Next, the structural model was measured through Smart-PLS bootstrapping. The structural model was evaluated including $\mathrm{R}^{2}$, beta and the corresponding t-values (Hair et al., 2014). As mentioned by Hair et al. (2014) and Soto-Acosta, Popa and Palacios-Marqués (2016), the bootstrapping process was applied to obtain the direct and moderating effect within the variables. The $\mathrm{R}^{2}$ value of this model is 0.781 and this indicates that $78.1 \%$ of the total variation of switching intention can be explained by all the four independent variables.

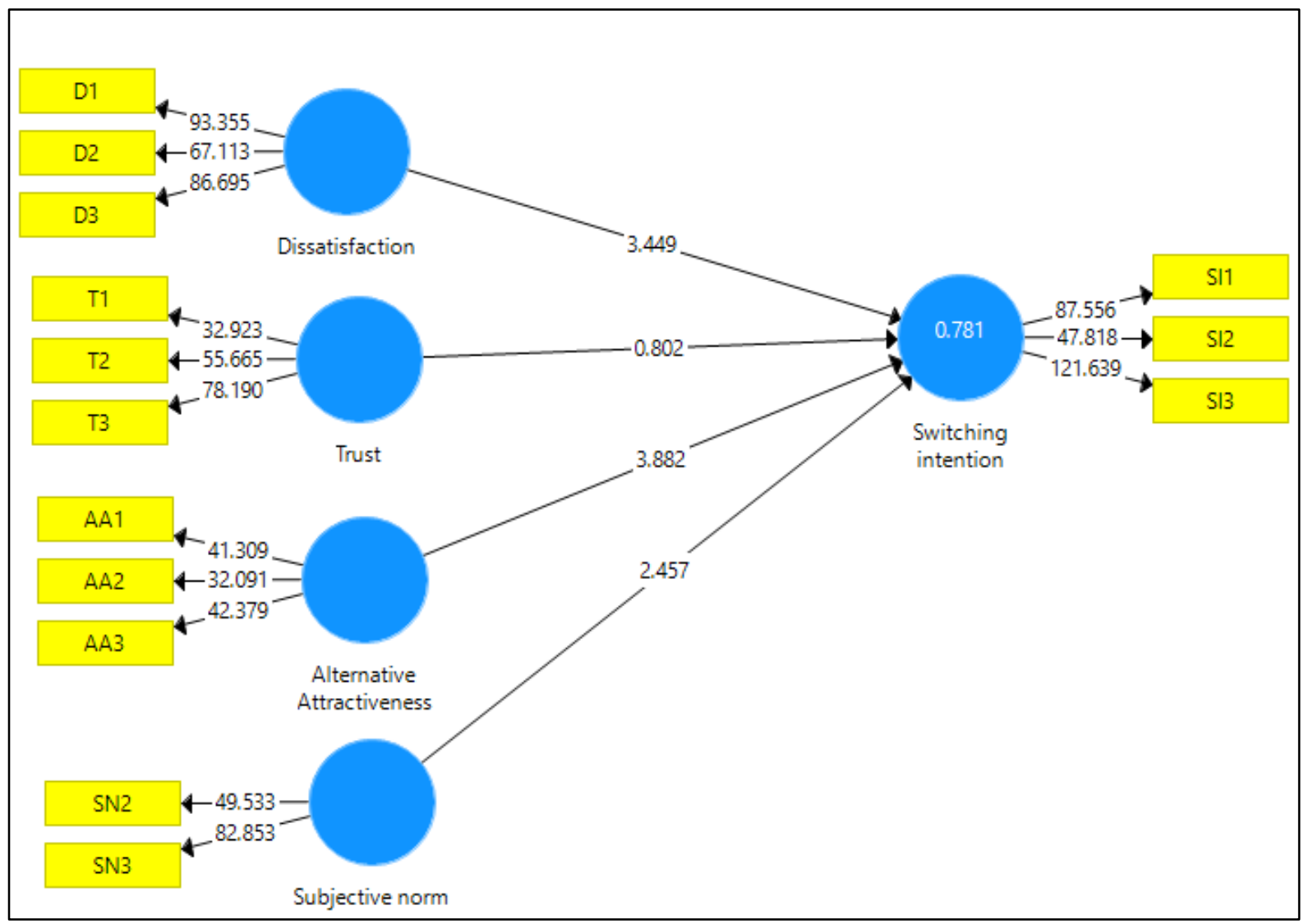

Figure 1: Structural Model

The result of the bootstrapping analysis shown in Table 4. The hypothesis testing result showed that dissatisfaction $(\mathrm{H} 1)$, alternative attractiveness $(\mathrm{H} 3)$ and subjective norm $(\mathrm{H} 4)$ have 
significant relationship toward user's switching intention on mobile wallet. However, trust (H2) do not showed significant relationship toward users' switching intention on mobile wallet.

Table 4: Result of The Hypothesis Testing

\begin{tabular}{|c|c|c|c|c|c|c|}
\hline Relationship & $\begin{array}{l}\text { Std } \\
\text { Beta }\end{array}$ & $\begin{array}{l}\text { Std } \\
\text { Error }\end{array}$ & t-value & $\mathbf{L L}$ & $\mathbf{U L}$ & Decision \\
\hline $\begin{array}{c}\text { Alternative } \\
\text { attractiveness -> } \\
\text { Switching intention }\end{array}$ & 0.349 & 0.090 & $3.882 * *$ & 0.203 & 0.497 & Supported \\
\hline $\begin{array}{c}\text { Dissatisfaction -> } \\
\text { Switching intention }\end{array}$ & 0.316 & 0.092 & $3.449 * *$ & 0.167 & 0.467 & Supported \\
\hline $\begin{array}{l}\text { Subjective norm -> } \\
\text { Switching intention }\end{array}$ & 0.264 & 0.107 & $2.457 * *$ & 0.079 & 0.435 & Supported \\
\hline $\begin{array}{c}\text { Trust -> Switching } \\
\text { intention }\end{array}$ & 0.082 & 0.102 & 0.802 & -0.073 & 0.262 & Not Supported \\
\hline
\end{tabular}

Out analysis result showed that there is a significant relationship between dissatisfaction and users' switching intention on mobile wallet. It shows that the users are dissatisfaction of the service quality and usability from the service provider. According to Chang, Liu, \& Chen (2014), Cheng, Yang, \& Lim (2009) and Fei \& Bo (2014), their studies proved that dissatisfaction with the current service provider will affect the users switching to another one. Lien et al. (2017) also showed that service quality will affect the user satisfaction and influence their usage intention. Thus, the low level of perceived service quality and the low level of perceived usage can lead to dissatisfaction of the users, so it triggers the intention of the user to switch (Song, Zhao, \& Sun, 2017).

Next, the analysis result showed that there is no significant relationship between trust and users' switching intention on mobile wallet. The result indicated that trust would not be affected by the switching intention, and this may be due to the majority of respondents being students and their age ranged from 18 to 24 years old. This group of users are more care about the service quality, usability and listen the recommendation or suggestion from their friends and family rather than trust. In addition, this group of users would choose those mobile wallets that provide good service, more benefits, features and rewards that could satisfy their needs.

In addition, our analysis result showed that there is a significant relationship between alternative attractiveness and users' switching intention on mobile wallet. Based on the research conducted by Kim et al. (2006), he proved that alternative attractiveness has an impact on users' switching intention. Hence, users will choose the alternative one if the other service provider is providing more features and benefits (Cheng, Yang, \& Lim, 2009). Furthermore, users would be attracted to switch to the alternative one because the alternative service provider may provide service that can match with their social needs (Hou, 2015).

Lastly, the analysis result showed that there is a significant relationship between subjective norm and users' switching intention on mobile wallet. Zhou \& Lu (2011) showed that the adoption and usage decision of users can be greatly influenced by social factors such as the choice of significant. Moreover, the users would perceive the alternative one as more attractive and have a stronger intention to switch because of people's recommendations (Hou, 2015). Copyright (C) GLOBAL ACADEMIC EXCELLENCE (M) SDN BHD - All rights reserved 


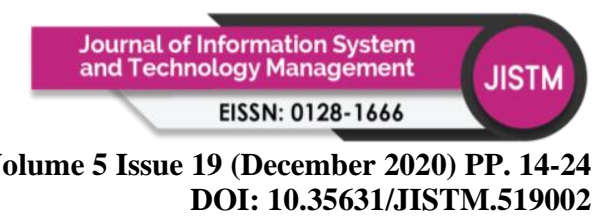

Lastly, if a user gets an invite from a significant other, they will likely to switch to the proposed one.

\section{Conclusion}

Our analysis result showed that dissatisfaction, alternative attractiveness and subjective norm have the significant relationship towards users' switching intention on mobile wallet. The research findings show dissatisfaction will affect the users' switching intention. This may be due to the service quality will directly affect the satisfaction of customers and indirectly affects the intention of use. Therefore, this research found that alternative attractiveness is another factor that affecting users' switching intention on mobile wallet. It is because users are more likely to move to the alternative when they perceived the main characteristics of an alternative mobile wallet service provider is better than the initial one. Moreover, subjective norm is another factor that would affect users' switching intention on mobile wallet as the users could be significantly influenced by social variables since their family, relatives and friends may be using a different type of mobile wallet and hence this could affect the user to switch it to another one. Lastly, trust is important because it would influence the users' desire to switch. In order to build trust with the users, the service provider should provide valuable contents and has engagement with customer so it could build up a trust between the service provider and users. The mobile wallet industry can continually to provide more benefits to the users in order to attract more people to use mobile wallet. Hence, it will help the industry to growth and push Malaysia towards a cashless society. Moreover, the service provider should keep improving their service quality to avoid users switching to another one. Lastly, the service provider must keep updating their product's features and attractiveness, so the users won't be so easily to switch to the another one.

\section{References}

Ahuja, A., \& Joshi, R. (2018). Customer Perception towards Mobile wallet. Journal of Business Management.

Ajzen, I. (1991). Theory of planned Behavior: Organizational behavior and human decision. Journal of Leisure Research,100(1), 96-109.

Bhattacherjee, A., Limayem, M., \& Cheung, C. M. (2012). User switching of information technology: A theoretical synthesis and empirical test. Information \& Management 49, 327-333.

Bansal, H. S., Taylor, S. F., \& James, Y. S. (2005). Migrating to new service Providers: Toward a unifying framework of consumers' switching behaviors. Journal of the Academy of Marketing Science, 33(1), 96-116.

Carr, M. (2007). Mobile payment systems and services: an introduction. In Mobile Payment Forum (Vol. 1, p. 12).

Casaló, L., Flavián, C., \& Guinalíu, M. (2008). The role of perceived usability, reputation, satisfaction and consumer familiarity on the website loyalty formation process. Computers in Human behavior, 24(2), 325-345.

Chang, H. H., Wong, K. H., \& Li, S. Y. (2017). Applying push-pull-mooring to investigate channel switching behaviors: M-shopping self-efficacy and switching costs as moderators. Electronic Commerce Research and Applications, 24, 50-67.

Chang, I. C., Liu, C. C., \& Chen, K. (2014). The push, pull and mooring effects in virtual migration for social networking sites. Information Systems Journal, 24(4), 323-346.

Cheng, Z., Yang, Y., \& Lim, J. (2009). Cyber Migration: An Empirical Investigation on Factors that Affect Users' Switch Intentions in Social Networking Sites, The 42nd Hawaii International Conference on System Sciences. 


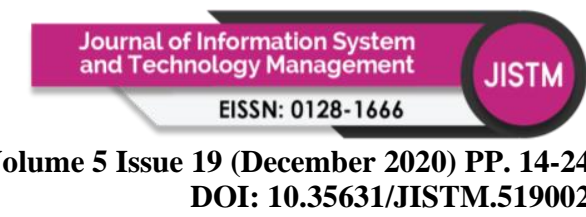

Flavián, C., Guinalíu, M., \& Gurrea, R. (2006). The role played by perceived usability, satisfaction and consumer trust on website loyalty. Information \& management, 43(1), $1-14$.

Fei, L., \& Bo, X. (2014). Do I Switch? Understanding Users' Intention to Switch between Social Network Sites, 47th Hawaii International Conference on System Science.

Gold, A. H., Malhotra, A., \& Segars, A. H. (2001). Knowledge management: An organizational capabilities perspective. Journal of Management Information Systems, 18(1), 185-214.

Hair, J. F., Ringle, C. M., \& Sarstedt, M. (2013). Partial least squares structural equation modeling: Rigorous applications, better results and higher acceptance. Long range planning, 46(1-2), 1-12.

Hair Jr, J. F., Sarstedt, M., Hopkins, L., \& G. Kuppelwieser, V. (2014). Partial least squares structural equation modeling (PLS-SEM) An emerging tool in business research. European Business Review, 26(2), 106-121.

Hou, A. C. (2015). Switching Motivations on Instant Messaging: A Study Based on Two Factor Theory. Springer Berlin Heidelberg.

Kasiri, L. A., Cheng, K. T. G., Sambasivan, M., \& Sidin, S. M. (2017). Integration of standardization and customization: Impact on service quality, customer satisfaction, and loyalty. Journal of Retailing and Consumer Services, 35, 91-97.

Keaveney, S. M., \& Parthasarathy, M. (2001). Customer switching behavior in online services: An exploratory study of the role of selected attitudinal, behavioral, and demographic factors. Journal of the Academy of Marketing Science, 29, 374-390.

Kim, S. S., \& Malhotra, N. K. (2005). A longitudinal model of continued IS use: An integrative view of four mechanisms underlying postadoption phenomena. Management Science, 51(5), 741-755.

Kim, G., Shin, B., \& Lee, H. (2006). A study of factors that affect user intentions toward email service switching. Information and Management, Vol. 43 No. 7, 884-893.

Lee, D., Moon, J., Kim, Y. J., \& Mun, Y. Y. (2015). Antecedents and consequences of mobile phone usability: Linking simplicity and interactivity to satisfaction, trust, and brand loyalty. Information \& Management, 52(3), 295-304.

Lien, C. H., Cao, Y., \& Zhou, X. (2017). Service quality, satisfaction, stickiness, and usage intentions: An exploratory evaluation in the context of WeChat services. Computers in Human Behavior, 68, 403-410.

Liu, Y., Li, H., Xu, X., Kostakos, V., \& Heikkilä, J. (2016). Modeling consumer switching behavior in social network games by exploring consumer cognitive dissonance and change experience. Industrial Management \& Data Systems 116, 801-820.

Nicolaou, A., \& McKnight, D. (2006). Perceived information quality in data exchanges: effects on risk, trust, and intention to use. Information Systems Research, Vol. 17 No. 4, 332351.

Oliver, R. (1981). Measurement and Evaluation of Satisfaction Processes in Retail Settings. Journal of Retailing,57, 25-48.

Peng, X., Scott, R., Prybutok, V., \& Sidorova, A. (2014). Product quality vs service quality in the mobile industry: Is there a dominant driver of customer intention to switch providers?. Operations Management Research, 7(3-4), 63-76.

Peng, X., Zhao, Y. C., \& Zhu, Q. (2016). Investigating user switching intention for mobile instant messaging application: Taking WeChat as an example. Computers in Human Behavior, 64, 206-216. 
Khan, M. A., Raheel, M., Chughtai, M. S., Raza, S., \& Rizwan, M. (2014). Attitude of people towards retention and switching: A study based on Nestle brand in Pakistan. Journal of Public Administration and Governance, 4(2), 146-165.

Ranganathan, C., Seo, D., \& Babad, Y. (2006). Switching behavior of mobile users: do users'relational investments and demographics matter? European Journal of Information Systems, 269-276.

Song, S., Zhao, Y., \& Sun, J. (2017). Understanding User's Switching Intention on Mobile. Computers in Human Behavior.

Soto-Acosta, P., Popa, S., \& Palacios-Marqués, D. (2016). E-business, organizational innovation and firm performance in manufacturing SMEs: an empirical study in Spain. Technological and Economic Development of Economy, 22(6), 885-904.

Steinbach, R. (2016). The Mobile Wallet Is Transforming Consumer Culture. Retrieved from Bit Rebels: https://bitrebels.com/technology/convenience-mobile-wallet/

Sun, Y., Liu, D., Chen, S., Wu, X., Shen, X. L., \& Zhang, X. (2017). Understanding users' switching behavior of mobile instant messaging applications: An empirical study from the perspective of push-pull-mooring framework. Computers in Human Behavior, 75, $727-738$.

Tan, Y. (October, 2018). Banking on the e-wallet in Malaysia. Retrieved from PWC Malaysia: https://www.pwc.com/my/en/perspective/deal-strategy/181003-banking-on-the-ewallet-in-malaysia.html

Wu, K., Vassileva, J., \& Zhao, Y. (2017). Understanding users' intention to switch personal cloud storage services: Evidence from the Chinese market. Computers in Human Behavior, 68, 300-314.

Ye, C., Potter, R., \& Potter, R. (2011). he role of habit in post-adoption switching of personal information Technologies: An empirical investigation. Communications of the Association for Information Systems, 28(1), 585-610.

Yoon, S. (2002). The antecedents and consequences of trust in online purchase decisions. Journal of Interactive Marketing, Vol. 16 No. 2, 47-63.

Zhang, K. Z., Cheung, C. M., Lee, M. K., \& Chen, H. (2008, January). Understanding the blog service switching in Hong Kong: an empirical investigation. In Proceedings of the 41st Annual Hawaii International Conference on System Sciences (HICSS 2008) (pp. 269269). IEEE.

Zhou, T., \& Lu, Y. (2011). Examining mobile instant messaging user loyalty from the perspectives of network externalities and flow experience. Computers in Human Behavior, 27(2), 883-889. 